Eskimos with trapping gear at George River, Northern Quebec, $58^{\circ} 32^{\prime} \mathrm{N}$., $65^{\circ} 53^{\prime} \mathrm{W}$.

Photograph courtesy of Carolyn MacDonald.

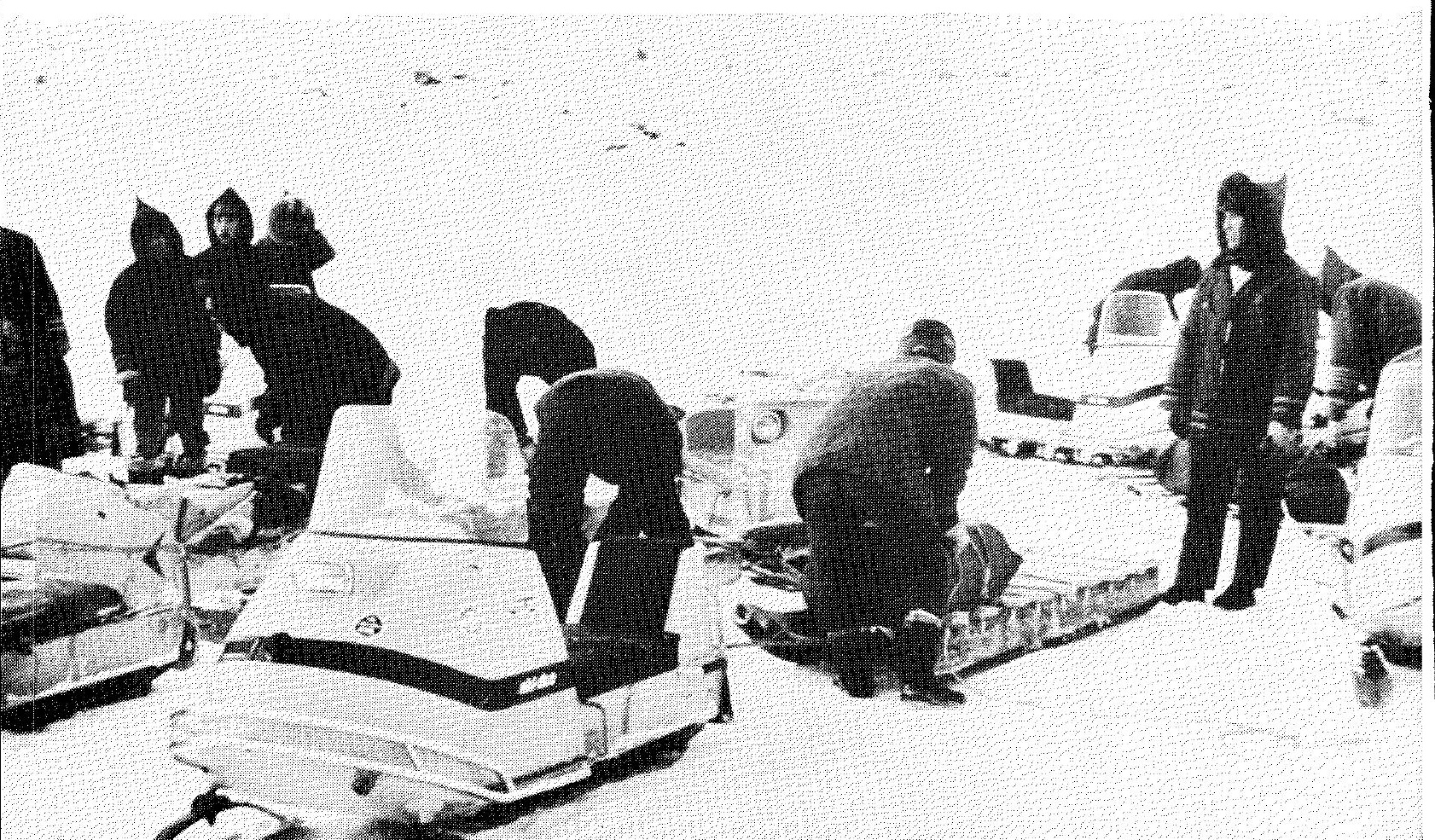




\section{The Use of Snowmobiles for Trapping on Banks Island ${ }^{1}$}

\section{PETER J. USHER ${ }^{2}$}

The village of Sachs Harbour on Banks Island, Northwest Territories, has been the outstanding example of a successful trapping community in northern North America for a generation (Usher 1971b). Trapping is still the full-time occupation of virtually every active male, and per capita income from trapping is higher than in any other settlement in the Arctic or Subarctic. Eighty-seven per cent of cash income at Sachs Harbour was derived from trapping during the years 1963 to 1967 , and the average income of full-time trappers from furs was $\$ 6,296$.

The sole basis of the fur harvest is the arctic or white fox, although the people also rely on 3 other major resources for their livelihood: caribou, seal, and polar bears. In recent years, the fewer than 20 trappers on Banks Island have accounted for as much as one-third of Canadian arctic fox production, indicating not only their own productivity but also the decline of trapping in other areas of the North. The top trappers have been known to obtain over 900 foxes in a peak year, and even in low years manage to get over 200; with foxes bringing about $\$ 20.00$ a pelt, it may readily be seen that potential income levels are high. Such productivity is not achieved anywhere else in the world, even in the Soviet Union despite greater encouragement of fur trapping there than in any other nation at the present time.

Certainly the Banks Island ecosystem provides an abundance of arctic foxes, but many and more extensive environments of a similar nature exist elsewhere in Canada as well as in the Soviet Union. The explanation for such high productivity lies not in ecology, or even primarily in economics, but rather in the unique history of the Canadian Western Arctic coast, and the resulting social and economic orientations of its people (Usher $1971 \mathrm{a}, \mathrm{b}$ ). The community and economy of Banks Island represent a distillation of this historical process.

The Bankslanders, as they call themselves, are acquisitive and proud. They are strongly motivated towards trapping as the most appropriate means of achieving both economic success and the prestige traditionally brought by conspicuous consumption. Although faced during the last two decades by rising prices for outside goods and relatively static prices for their produce, they have consistently maintained their economic position through improved trapping technology and greater effort. The Bankslanders have a tradition of innovation. They are quick to test new means of production, and to invest money in high

\footnotetext{
1Based on a paper presented at the 69th annual meeting of the American Anthropological Association, San Diego, California, 19 November 1970.

2Northern Science Research Group, Canada Department of Indian Affairs and Northern Development.
} 
quality capital goods which have proven their worth. Even trappers in their twenties and thirties are highly skilled, and none spare effort on the trapline. The trapping and hunting system on Banks Island is probably the most modern of its type in the world, relying on the best available technology, and the most productive systems of organization and marketing.

Sachs Harbour is not a long established community, nor was its hinterland traditionally occupied. Hardly any of the trappers were born on Banks Island, but rather most chose as young men to make their homes and livelihood there. A true pioneer people, they have maintained a way of life they value strongly, and have created a community they feel most suitable for raising their children. Although they visit the mainland frequently, and have relatives there, they disdain to live in what they perceive to be a society without economic opportunity, without adequate supplies of country food, no longer in control of its own destiny, and characterized by drunkenness, delinquency, brutality, poverty and aimlessness.

\section{THE INTRODUCTION AND USE OF SNOWMOBILES, 1961-67}

Banks Island is probably as good a physical environment as any for making efficient and effective use of snowmobiles for hunting and trapping. Characteristically arctic, the island is entirely treeless, and only in one or two of the more southerly valleys are there even stands of willows. The topography is rugged in the extreme north and south of the island, but most of the trapping and hunting is in the central lowland physiographic province, which is characterized by broad, flat river valleys and low, gently rolling interfluves. The west coast is a complex one of bays and spits, and the fast ice usually forms smoothly with a minimum of fracturing and ridging, and no tide cracks. Old ice from the previous season is sometimes incorporated, but presents only isolated and easily avoidable obstacles.

Bedrock is rarely seen in this area, and large boulders are infrequent. A thin vegetation mat of lichen, mosses or sedges covers the sandy or silty subsoil and although the interaction of vegetation, permafrost, moisture and slope creates tussocks, hummocks, polygons and soil stripes, the ground surface is not nearly as rough as, for example, the frost-riven boulder fields which are typical of flat areas in many other parts of the Canadian Arctic.

Snowfall, although very light by southern Canadian standards, remains on the ground for perhaps nine months. Nearly continuous winds create drifting which soon obscures the landscape, and by the latter part of October provides an extremely hardpacked travelling surface, although these same winds can keep exposed knolls and ridges bare well into winter. Not until June does the snow thaw, causing the traveller to sink into the drifts instead of riding over them.

Snowmobiles were first introduced to Banks Island in 1961, when 3 of the leading trappers purchased them. All were of the same brand, although one was of a different model. As is characteristic, this event followed a peak fox season, when these men had a surplus of funds for such investment. By 1965, two of these machines were no longer operable, and one was used only around the settlement. Operating costs had been found to be about 6 or 7 cents per mile, but deprecia- 
tion costs (which could only be crudely estimated) may well have approached $\$ 1.00$ per mile. Although potentially a much more rapid form of transport, these machines had no greater payload (about 1,000 lbs.) than a team of 9 dogs which was then about the average.

More important, however, was the unreliability of these vehicles and the difficulties of operating and maintaining them, particularly in very cold weather when the drivers, too, suffered more from low temperatures than they had with dogs. One man kept his machine in his tent so it could be warmed up before starting in the morning, and even then was plagued by mechanical failures. An additional problem was that even upon returning to the settlement, there was considerable difficulty and delay in obtaining spare parts. Air service in winter was at that time highly irregular, and telecommunications with the outside not always reliable. A man depending solely on a machine would have faced the possibility of being rendered immobile for long periods during the trapping season, and this in spite of the very high mechanical aptitude of most of the trappers. Consequently when the 3 owners used snowmobiles on their main traplines dogs were always taken along as they never felt sufficiently confident of their machines' reliability on long trips. In cases where two men trapped together, one travelling by snowmobile and the other with dogs, it was found that for short periods the dogs would chase the machine, and go faster, but in the long run the dogs tired, so that a full day's travel covered no greater distance than would have been the case with dogs alone, although travelling time might have been slightly reduced.

It was also found that in making the actual trap set, gasoline spills or even working with gasoline-stained mitts would spoil it, so they had to leave the machine some distance from the trap, and use separate mitts or gloves for machine operation and trap preparation. There was also some feeling that the combustion odour would scare foxes away, but not all agreed on this point, and little evidence has been acquired since to support or refute this notion. Therefore, although in theory the machine allowed increased speed on the lines and consequently more trips, in practice the snowmobile owners found little or no advantages in mechanized travel and after the first purchases, no further snowmobiles were brought in for 5 years. This was chiefly because of their unreliability, and their failure to improve trapping productivity, but probably also because a number of poor trapping years were experienced and few men had the cash or credit to purchase them. Snowmobiles were seen largely as convenient toys - useful for hauling ice or fuel around the village, and for going up to the weather station for movies and mail, but hardly warranting their expense on that account. And certainly the individualistic Bankslanders would never have purchased them on a share basis.

By 1966, however, there were several new brands available, and another 3 trappers purchased different models of a particular brand. Two of them used the machines only for running daylines near the settlement, and did not travel any distance away. That winter being unusually good for foxes, one of these men (a full-time wage employee) was able to pay off both his initial capital cost and his operating costs just by trapping at night and during weekends near home. Another, running a relatively short line, used his snowmobile on several trips and 
was well pleased with his model, which he found particularly reliable. Although his partner went with dogs, so that maximum speeds could not be achieved, the potential of this reliable and serviceable machine was readily seen. This trapper also appreciated the fact that to go in the desired direction he had only to turn the handlebars, and not shout at his dogs.

As a result of these experiences, and the excellent harvest obtained that season, nearly every trapper purchased snowmobiles the following summer, chiefly of the same brand. This was the real turning point in the use of snowmobiles for trapping at Sachs Harbour.

Fortunately, we have comprehensive data on economics and trapline productivity for the last 3 years of the "dog era" (1964-67) which provide a basis for comparison with the new trapping practices developed since then using the snowmobile (for a detailed analysis of this material, see Usher 1971c).

\section{THE USE OF THE SNOWMOBILE, 1967-70}

Twenty-six snowmobiles were purchased by the Bankslanders between the summer of 1967 and the fall of 1970 . Our analysis, however, is restricted to the 19 machines purchased during that time by the 10 men who were trapping fulltime during the $1969-70$ season.

These 19 machines consisted mainly of 2 brands; 1 was of another type. There have been in effect two generations of snowmobiles at Sachs Harbour: those purchased in 1967 or 1968 , most of which were the same brand as that introduced by the 3 trappers in 1966; and those purchased in 1969 or 1970 which were mainly of a different brand.

Both generations have proven reasonably reliable, and there have been very few major breakdowns on the trail where the owner had to walk any distance. Of the first generation machines, 4 were still operating in late 1970; those that were not had had an average life of 2 years. In one or two cases, new engines were installed, but usually the entire machine was written off. All of the second generation were still in operation by late 1970 although of course their average life to that date had been less than a year. It seems safe to assume that a wellmaintained snowmobile should last at least two seasons.

The transition to snowmobiles was by no means complete, however. Only 3 of the 10 trappers used them exclusively during the 1969-70 trapping season. Eight of them still maintained a full complement of dogs, although one team was not used; the average team consisted of just over 9 dogs, indicating no reduction since 1967. One man still used dogs exclusively although he trapped with his son who sometimes used a machine. There had been an increased tendency to travel in pairs in order to reduce the hazard of breakdown, but this problem was also overcome by purchasing large quantities of spare parts to take on the trail and also, in a few cases, by taking a number of dogs. In such cases they might pull an extra load or be allowed to run free. Most men liked to take one dog along when travelling by snowmobile. In an emergency, this dog could pull a small toboggan so that a stranded trapper need not also manhaul his survival 
gear, and along the coast, where there is a danger of bears entering the camp, it served as a watch dog.

Most common, however, was a mixed use of dogs and machine during the trapping season. The trappers found the machines most useful in the spring months, especially on the last trip in April, when the days are long, the weather is not so cold, and the task is largely one of pulling traps rather than setting or resetting them. Of 53 trapping trips made during 1969-70, 22 were made with snowmobiles alone and 21 with dogs alone. The other 10 were made either with a combination of dogs and machines by the same trapper, or the snowmobile driver travelled with a dog driver so that the machine was not used at full efficiency. The 10 trappers travelled a total of 11,372 miles on their lines, but snowmobiles were used for 7,482 miles, and dogs for 4,515, indicating the overlap.

During the 3 years under review snowmobiles were also used for hunting, although there was some disagreement about their utility for that purpose. Rough ice would prevent their use in seal hunting, but that was seldom a problem because, as previously noted, the ice in the vicinity of Sachs Harbour is normally smooth. There are still conflicting views as to whether engine noise scares or attracts animals. Some hunters state that caribou or hauled-up seals are frightened by the noise; more rarely, others have observed animals to remain and watch the unfamiliar object approaching, out of curiosity. One must also consider the possibility that animals unused to snowmobiles and thus unafraid of them could become wary in the future, just as well-hunted deer herds generally bolt at the sound of a rifle. This has reportedly already occurred in Alaska (Hall 1971, p. 249). On the other hand, it could be argued that in the case of caribou it should be possible for a machine going at top speed to run them down.

Also evidenced by the end of 1970 was a change in some patterns of seasonal activity. In particular, October caribou-hunting declined, because the ground is not sufficiently snow-covered at that time for safe snowmobile operation. Consequently, such hunting tended to be combined with the first trapping trip in November. The practice of toggling traps before season also appeared to have declined for the same reason. Both these developments may have reduced early season efficiency slightly. Finally, snowmobiles were used frequently around the settlement for haulage and for visiting.

\section{ECONOMIC IMPLICATIONS}

When dogs were used for trapping, the total annual cost of a trapping and hunting outfit was about $\$ 1,290$, divided almost equally between depreciation and operating costs (Usher 1971c, p. 96). Here we refer to the total outfit, because trapping success is significantly dependent on the ability of the trapper to obtain an adequate supply of country food for his dogs and his family. The chief capital costs were in traps, firearms, camping equipment, and the means of transport. Of the latter, the canoe and outboard were the most expensive items. These were used to obtain sealmeat for dogfeed, and thus were an indirect investment in trapping. Dogs were not included as a capital expense, since they were bred 
from existing stock, although the cost of purchasing a good team of 9 dogs on the open market was over $\$ 500$. Operating costs consisted largely of ammunition, cornmeal for dogfeed, and various fuels for stoves, lamps and outboards.

A method was devised for allocating production costs to each activity, incorporating both direct and indirect costs (Usher 1971c, p. 97). The direct costs of dogteam travel, based on 1,620 miles per year, were $\$ 0.21$ per mile. This included cornmeal, naphtha gas for stoves, and the depreciation on harnesses, doglines and chains. When the cost of dogfeed production was included, however, a total figure of $\$ 0.60$ per mile was obtained. It was also determined that the average production cost per fox pelt was $\$ 4.34$ (assuming fixed costs and variable returns, during the cycle this can range from about $\$ 2.00$ to $\$ 15.00$ per pelt), of which $\$ 3.40$ consisted of dogteam maintenance. The rest consisted of depreciation on traps and camping gear.

Rather higher costs are incurred in snowmobile travel. The snowmobiles used at Sachs Harbour cost about $\$ 1,000$ landed. (There is some variation of course, depending on both the brand and the means of shipment, although one mail order house is now shipping goods north freight-free). An adequate supply of parts adds perhaps another $\$ 300$, whether or not they are actually used, since once a new machine is purchased, the old parts may no longer be usable. Depreciation on capital investment is thus about $\$ 650$ annually. The new models appear to use more fuel than those of the early 1960's, and the trappers report a gasoline consumption of about 8 miles per gallon, or at local prices, an operating cost of nearly $\$ 0.20$ per mile. The men who used snowmobiles for trapping in the winter of 1969-70 travelled an average of 831 miles each on their traplines. Assuming use around the settlement and in other hunting endeavours, a machine would probably travel about 2,000 miles during its 2-year life, giving a depreciation cost of $\$ 0.65$ per mile. If they are used to the exclusion of dogs on the trapline, mileage increases and this cost could be reduced to perhaps $\$ 0.50$ per mile. Even so, this is a significant increase over the cost of dogteam travel.

When dogs are used as well as machines the increase in cost is very great indeed. Those men who used both, though not necesarily together, travelled with dogs an average of 548 miles each during the season, out of a potential mileage of 1,064 had they used dogs exclusively. Unfortunately, no reduction in expense resulted, since the total annual cost of maintaining a team is fixed, regardless of how much the team is used. In effect their dogs were used at 50 per cent efficiency, driving their cost per mile travelled to perhaps $\$ 1.20$. It seems likely that this practice of using dogs and machines together is transitory, and that it is only a matter of time before the trappers get rid of all but one or two of their dogs, which can then be fed on scraps at no extra cost. Thus a decline in seal hunting appears inevitable although, depending on the strength of the fur market, people may sometimes find it advantageous to hunt seals for their skins alone. Yet even if there is no use for seals at all, certain costs at present associated with hunting them will persist, for people will continue to use canoes and outboards for enjoyment and haulage. Hence, while some reduction in both operating and depreciation costs will result, the canoe and outboard will necessarily be far less productive investments 
than formerly. And one cannot discount the possibility that both boats and snowmobiles will depreciate faster than necessary, because of the tendency to keep up with the new models even though the old ones may still be serviceable. In any case, for the present, the inclusion of snowmobiles in the trapping and hunting outfit, without any corresponding reduction in other costs, will raise the annual expense from $\$ 1,290$ to over $\$ 2,200$. Even if dogs are dispensed with, no more than $\$ 600$ will be saved annually. Such an increase in costs is economically justified if production can be raised correspondingly: that is, given the current average price of foxes, an average increase of perhaps 20 saleable pelts per year.

\section{Production potential}

In theory, the snowmobile provides the trapper with several options for increasing his productivity. Speed on the trail can be increased, enabling a greater number of trips and of trap checks (a unit of effort measurement developed for line trapping - see Usher, 1971c, pp. 33-34), or permitting extra time at home during the winter. In peak years, an increase in trapline visits would both increase productivity and reduce losses. In poor years, the snowmobile could enable men to run longer lines, especially in spring, to take advantage of hitherto unexploited country, and increase the probability of picking up "spring runs". In the coldest and often most unproductive months of January and February, the men could make their monthly trips in perhaps 7 to 10 days instead of the current 2 or 3 weeks, and have more leisure time at home.

The present analysis is restricted to the input and output during the 1969-70 season of the 10 full-time trappers on their main lines. Short daylines set around the village, whether by regular trappers or wage employed men, are not included.

It should be noted at the outset that although trapping returns fiuctuate greatly, based on the fox cycle, effort inputs vary by no more than 10 or 15 per cent about the mean from year to year. In fact, the partial introduction of snowmobiles by 1970 had had little general effect on either effort inputs or productivity, since the values of the 21 indices used in measuring these showed no significant change in 1969-70 from those of 1964-67. Even an analysis of trips made exclusively by snowmobile in the winter of 1969-70 shows few significant differences, except at certain times of the year.

The length of traplines has not generally increased, nor has the number of traps set. One trapper felt that he tended to set his traps somewhat further apart when travelling by machine. While this may be true for certain parts of individual traplines, no significant differences were observed in either the individual or collective trap density indices from the average of about 4 per mile. The most significant change comes, not unexpectedly, in the distance travelled per day, although there is a marked seasonal variation. For the pre-Christmas period, there was no change from the old rate of about 12 miles per day. This is because the bulk of the work at that time involves the building of mounds and the setting of traps. Since travel time accounts for such a small proportion of the total work time, the use of the snowmobile apparently brings little change. During the January-February period, however, snowmobile drivers went over 19 miles per day, compared with less 
than 15 miles by dog drivers, and during March and April, about 32 miles per day compared with 21 , for reasons already noted. The yearly index, however, shows an increase of only about one third (15.6 to 20.3 miles per day) in snowmobile speed over dogs, which seems lower than one might have expected. The snowmobile drivers did not make any more trips than usual, and hence during the winter and spring spent rather less time on the trail than the dog drivers, although still making similar effort in terms of trap checks.

This suggests that, in poor or average years at least (1969-70 was an average year), the trappers will use their snowmobiles to give themselves more leisure time rather than increase their trapping effort, although a marked decline in fox prices could spur them to increased productivity. They may still, of course, use it to increase productivity in the special cases noted above. The proof of this will come with the analysis of data from peak fox seasons. The critical time here will be during the early season runs, when trapped foxes are preyed on by live ones and losses, especially at the far ends of the traplines, are heavy. Yet the apparent inability to increase speed on the trapline during November and December using snowmobiles suggests that little or no change may occur. Pre-Christmas productivity can only rise through being able to make a third trip during that time, and this now seems doubtful. During ordinary years the snowmobile will almost certainly not affect the loss rate - in 1969-70 it was about average at 13 per cent.

It seems unlikely, then, that the average trapper will in fact obtain 20 extra foxes annually, although in good years he may do that and more. The willingness of the trappers to incur extra costs is perhaps a measure of the value they place on the convenience and additional leisure time afforded by the snowmobile. There is already evidence from previous years that the trappers are willing to forgo maximum economic returns, or even engage in unprofitable activities, for the sake of convenience, leisure, or recreational enjoyment, to a limited degree at least.

On the other hand, although the snowmobile may not directly increase trapline productivity, by reducing the importance of the summer seal hunt it frees a large block of time at a season when wage labour is most likely to be available on a casual basis, either locally or on the mainland, so that total income may well be increased.

\section{ECOLOGICAL IMPLICATIONS}

Mean trapping returns by cycle have been fairly consistent on Banks Island over the last 40 years, and there is little or no evidence that overtrapping occurred either before or during the period of investigation. The traplines radiate out from the settlement in a quadrant, and there are some signs that towards the end of the season, returns on the near sections of the lines diminish, but by this time the most intensive trapping takes place further away.

In view of the apparent preference for leisure over increased productivity it would appear that the introduction of the snowmobile will not lead to overharvesting of foxes, although it may in some cases reduce losses, which would be beneficial. Nor will it be likely to lead to increased hunting pressure on big game, 
including caribou. The seal harvest has already declined, and will continue to do so unless pelt prices improve, but there has been in any case no evidence of overharvesting of this resource. The seal population appears to be migratory, and the Bankslanders may not be its major harvesters. The decline of the seal catch at Sachs Harbour alone may therefore be of little consequence to the seal population as a whole. As in many instances of technological advancement, one sees an increased reliance on non-renewable resources, and decreasing dependence on renewable ones; a tendency lamentable on a world scale but inconsequential on Banks Island.

With regard to the effects of snowmobile activity on animal behaviour, there is little or no evidence of harm. The level of noise and fumes generated by such activity would seem to be negligible, and the more specific effects on trap sets can be obviated with a little care. This whole question has been clouded, however, by seismic exploration for oil on the island which began in October 1970, and the controversy surrounding this event.

\section{SOCIAL IMPLICATIONS}

Contrary to the experience in many other parts of the Arctic, the social effects of the snowmobile on Banks Island have been very limited, and will probably continue to be so. Sachs Harbour is by no means a traditional community. In their commercial orientation, the Bankslanders are totally different from their aboriginal forebears. They pursue a contact-traditional activity, to be sure, but in a modern context. Already acculturated in so many ways, and strongly dependent on external markets and imported goods, the Bankslanders can be little affected by the snowmobile. Those seeking to document dramatic changes in attitudes and living patterns resulting from the snowmobile would be advised to examine rural Ontario and Quebec, where the arrival of the snowmobile appears to have been the biggest event since electrification, instead of Banks Island.

Changes in social stratification, such as have been observed among Lapp reindeer herders (Pelto et al. 1968), have not occurred on Banks Island, since the trapping endeavour is highly individualistic and involves no division of labour within the community. A trapper is still judged by his ability and his productivity, on which the snowmobile will have little effect. Some men are obviously more successful and wealthier than others, but the snowmobile does nothing to alter this relationship. The top men will have the best machines, but so previously had they the best rifles, canoes, outboards, record players, radios and houses. The Bankslanders are strongly technologically oriented - the snowmobile is just another item in a long inventory.

It seems doubtful that the snowmobile will affect either residence or visiting patterns within the village. Nor, by virtue of its own mobility, will the snowmobile cause significant changes in intercommunity travel patterns. The nearest community (Holman Island) is over 200 miles distant by surface travel; only a minority of the Bankslanders have kinship or friendship ties there, and it offers no attraction as a higher order central place. Travel between the two communities will 
doubtless increase, but with minimal impact on most residents. Tuktoyaktuk and Inuvik, to which most Bankslanders are more strongly oriented, are not only 255 and 320 airmiles distant respectively, but also lie across the Beaufort Sea and so are inaccessible by snowmobile at any time of year.

The snowmobile may, however, have an indirect effect on travel and residence patterns. By freeing trappers from the summer seal hunt it will allow them to seek wage employment at that season. Indeed, the extra costs incurred by snowmobile ownership may serve as an incentive to do so. Yet even with the current growth of construction and oil exploration on the island, there will probably not be enough wage work at Sachs Harbour for all trappers. Accordingly there may be increased migration to the mainland during the summer months.

The interrelations between wage labour and snowmobile ownership, commented on by many in other parts of the North (viz. Hall, 1971, Moyers, 1970, Smith, in press), are of little significance at Sachs Harbour. Full-time trappers earn as much or more than those employed in steady wage positions, hence there is no difference in their ability to purchase snowmobiles. Nor do wage earners, as a result of their access to improved technology, unfairly compete with those who rely solely on the land for their income. In fact, wage employees cannot range nearly as far as the full-time trappers, since they do not have the time. Their share of the harvest has always been small, and the snowmobile will not change this.

\section{CONCLUSIONS}

The snowmobile has been gradually integrated into the Banks Island trapping system over a decade. Caution and astuteness have marked its acceptance. It would appear that it will not have any profound effects on the system.

Temporarily the snowmobile constitutes a considerable extra economic burden, and although this will very likely diminish, it cannot but increase production costs. Although it will probably not increase trapline productivity significantly, it will provide more leisure time during the trapping season, and more free time for the assumption of temporary wage positions during the summer months. As a result, total net income will probably increase, and with reduced reliance on fox pelts as the sole source of cash, the cyclic pattern of income from year to year should be reduced.

Harvests of all species should remain within sustainable limits, and some species will be harvested at lower levels than at present. There do not appear to be any serious effects on animal behaviour.

The snowmobile is only one of many forces that will change the social system at Sachs Harbour. The encroachment of government administration and private resource development, both of which accelerated greatly in the summer of 1970, will be of far more profound consequence than the snowmobile. Data on trapping effort and productivity from 1970 onwards will therefore have to be interpreted in the light of these events as well as of the transition to snowmobiles, which is now, in 1972, virtually complete. 


\section{REFERENCES}

HALL, E. S. JR. 1971. The 'iron dog' in northern Alaska. In: P. and J. Lotz (eds.), Pilot, not commander: essays in memory of Diamond Jenness, special issue of Anthropologica, 13 (1 and 2): 237-54.

MOYERS, D. 1970. Wage labour and skidoos. A paper presented at the 10 th annual meeting of the Northeastern Anthropological Association, Ottawa.

PELTo, P. et al. 1968. The snowmobile revolution in Lapland. Journal de la Société FinnoOugrienne, 69: 3-42.

SMITH, D. G. In press. Natives and outsiders: pluralism and the culture of marginality in the Mackenzie River delta. Northern Science Research Group, Department of Indian Affairs and Northern Development, Ottawa.

USHER, P. J. 1971a. The Canadian western Arctic - a century of change. In: P. and J. Lotz (eds.), Pilot, not commander: essays in memory of Diamond Jenness, special issue of Anthropologica, 13 (1 and 2): 169-83.

1971b. The Bankslanders: economy and ecology of a frontier trapping community. Volume 1: History. NSRG-71-1, Northern Science Research Group, Department of Indian Affairs and Northern Development, Ottawa. $124 \mathrm{pp}$.

1971c. The Bankslanders: economy and ecology of a frontier trapping community. Volume 2: Economy and ecology. NSRG-71-2, Northern Science Research Group, Department of Indian Affairs and Northern Development, Ottawa. 169 pp. 